\title{
Analisis Tingkat Getaran dan Kebisingan Vibrating Screen Crusher FC 02 pada PT Mifa Bersaudara
}

\author{
Herdi Susanto ${ }^{1, a)}$, Dailami ${ }^{2, b)}$, Kamarullah ${ }^{3, c)}$ \\ ${ }^{1,3}$ Prodi Teknik Mesin, Fakultas Teknik, Universitas Teuku Umar \\ Jl. Alue Penyareung Kabupaten Aceh Barat, Aceh, Indonesia 23615 \\ ${ }^{2}$ Jurusan Teknik Mesin, Politeknik Negeri Lhokseumawe \\ Jalan Banda Aceh - Medan, Buketrata, Lhokseumawe, Aceh, 24301 \\ a) e-mail : herdisusantu@utu.ac.id (corresponding author), b) email : dailamiteknik@gmail.com \\ c) email : kamarullah344@gmail.com
}

\begin{abstract}
Abstrak
Tujuan dari penelitian ini adalah menganalisis tingkat getaran dan kebisingan pada perangkat vibrating screen crusher FC 02 pada PT. MIFA Bersaudara. Getaran diukur dengan menggunakan alat vibration meter, kebisingan diukur dengan sound level meter dengan tipe digital. Pengukuran dilakukan pada sumbu $\mathrm{x}, \mathrm{y}$ dan $\mathrm{z}$ pada setiap titik pengukuran. Hasil penelitian menunjukan bahwa nilai tingkat getaran pada vibrating screen crusher $\mathrm{FC} 02$ pada sumbu $\mathrm{x}$ dengan nilai velocity $28,56 \mathrm{~mm} / \mathrm{s}$, sumbu y nilai $29,82 \mathrm{~mm} / \mathrm{s}$ dan sumbu z nilai velocity $25,46 \mathrm{~mm} / \mathrm{s}$. Sedangkan nilai Acceleration pada sumbu x sebesar $20,7 \mathrm{~m} / \mathrm{s}^{2}$ nilai $30,86 \mathrm{~m} / \mathrm{s}^{2}$ pada sumbu y dan z sebesar $21,42 \mathrm{~m} / \mathrm{s}^{2}$. Sedangkan nilai kebisingan menujukan bahwa nilai rata-rata pada sisi kanan menujukan sebesar 99,6 dBA pada sisi kanan dan pada sisi kiri sebesar 101,7 dBA. Upaya yang dilakukan untuk mengatasi masalah yaitu dengan cara tidak mengoperasikan vibrating screen crusher FC 02 melebihi batas maksimum yang di anjurkan $60 \mathrm{dBA}$ dan maksimum yang diperbolehkan yaitu 70 dBA sehingga dapat mencegah terjadinya permasalahan kenyamanan, kesehatan, dan keselamatan kerja. Operator berserta karyawan disarankan berada dilokasi tersebut tidak lebih dari 15-30 menit, jika lebih dari waktu tersebut harus menggunakan earmuff safety.
\end{abstract}

Kata Kunci : getaran, kebisingan, vibrating screen crusher FC 02

\begin{abstract}
The purpose of this study was to analyze the vibration and noise levels in vibrating screen crusher FC 02 equipmentat PT. MIFA Bersaudara. Vibration is measured using vibration meter tools, noise is measured by sound level meters with digital types. Measurements are made on the $x, y$ and $z$ axes at each point of measurement. The results of the study on the ground showed that the vibration rate value on vibrating screen crusher FC 02 on the $x$ axis with a velocity value of $28.56 \mathrm{~mm} / \mathrm{s}$, the y axis with a value of $29.82 \mathrm{~mm} / \mathrm{s}$ and the $z$ axis velocity value of $25.46 \mathrm{~mm} / \mathrm{s}$. While the acceleration value on the $x$ axis of $20.7 \mathrm{~m} / \mathrm{s} 2$ value $30.86 \mathrm{~m} / \mathrm{s} 2$ on the axis y and $z$ of $21.42 \mathrm{~m} / \mathrm{s} 2$. While the noise value indicates that the average value on the right side is $99.6 \mathrm{dBA}$ on the right side and on the left side of $101.7 \mathrm{dBA}$. Efforts are made to overcome vibration and noise problems by not operating Vibrating screen crusher FC 02 exceeds the maximum recommended limit of $60 \mathrm{dBA}$ and the maximum allowed is $70 \mathrm{dBA}$ so as to prevent problems of comfort, health, and work safety. Operators and employees are advised to be in the location no more than 15-30 minutes, if more than that time must use earmuff safety.
\end{abstract}

Keywords: noise, vibrating screen crusher FC 02, vibration

\section{PENDAHULUAN}

Propinsi Aceh memiliki sumber energi batu bara potensial yang tersebar di beberapa daerah seperti Meulaboh, Aceh Barat, Singkil, dan Nagan Raya. Sektor pertambangan merupakan sektor terpenting di Propinsi Aceh mengingat peranan sektor tersebut dalam pembentukan PDRB yang mencapai 30,95\%. Pasca Tsunami, Barat selatan aceh prospek besar untuk dikembangkan dengan kemajuan dan teknologi yang ada khususnya dibidang industri petambangan sehingga banyak perusahaan-perusahaan besar pada bidanng tersebut yang mendirikan perusahaan di daerah Barat Selatan Aceh. PT. MIFA Bersaudara memiliki luasan wilayah konsesi seluas 3.134 Hektar (Ha) di wilayah kabupaten Aceh Barat yang berlaku sampai dengan 2025 [1]

Pentingnya uji pengukuran gertaran dan kebisingan yang ditimbulkan alat kerja Vibrating screen ini dimana kebisingan merupakan terjadinya suatu bunyi yang tidak dikehendaki sehingga dapat menimbulkan gangguan terhadap kenyamanan dan kesehatan [2]. Kebisingan dapat menyebabkan kerusakan pada indra pendengaran, baik yang sifatnya permanen atau bersifat sementara yang dipengaruhi oleh frekuensi dan intensitas terpapar oleh kebisingan[3]. Sedangkan getaran merupakan gerakan seragam yang terjadi secara berulang ulang dari suatu 
benda dalam tempo yang cepat. Getaran yang disebabkan pada saat mesin dioperasikan akan menimbulkan getaran mekanis[4].

Vibrating screen sendiri merupakan alat yang digunakan untuk memisahkan ukuran meterial hasil proses peremukan berdasarkan besarnya ukuran dari lubang bukaan (opening) dengan satuan milimeter (mm) atau biasa di sebut dengan mesh [5]. Sesuai dengan Keputusan Menteri Kesehatan tentang Lingkungan Kerja Perkantoran dan Industri Nomor 1405/MENKES/SK/XI/2002 menyatakan bahwa ambang batas kebisingan adalah $85 \mathrm{~dB}$ untuk 8 jam kerja/hari.

Oleh karena itu, perlu adanya penelitian yang dilakukan untuk mengetahui sejauh mana gertaran dan kebisingan yang ditimbulkan alat kerja Vibrating screen ini diakarenakan dampaknya akan dapat merusak pendengaran jika dibiarkan dalam jangka panjang. Kebisingan dapat menyebabkan meningkatnya kelelahan dan terganggunya konsentrasi pekerja sehingga terjadi kesalahan-kesalahan saat bekerja. Kerja terus-menerus di tempat bising berakibat kehilangandaya dengar yang permanen dan tidak dapat pulih kembali, kebisingan bersumber dari mesin dan peralatan produksi yang digunakan dalam suatu perusahaan. Dengan demikian penelitian ini perlu dilakukan untuk menjamin keselamatan dan kesehatan kerja.

\section{METODE PENELITIAN/EKSPERIMEN}

Objek pengukuran pada penelitian ini adalah vibrating screen crusher FC 02 yang berada di PT. MIFA Bersaudara beroperasi di Kabupaten Aceh Barat, Provinsi Aceh. Alat ukur getaran yang digunakan vibrationmeter dan alat ukur kebisingan adalah sound level meter. Pengukuran dilakukan pada sumbu $\mathrm{x}, \mathrm{y}$ dan $\mathrm{z}$ setiap titik pengukuran dengan jarak ukur 1 meter. Pengukuran dilakukan dari tanggal $11 \mathrm{~s} / \mathrm{d} 13$ maret 2021. Parameter getaran yang diukur adalah percepatan (acceleration), dan kecepatan (velocity). Sedangkan parameter kebisingan adalah desibel (dBA). Pengolahan data pengukuran dilakukan dengan menggunakan aplikasi microsoft excel dalam bentuk tabel dan direpresentasikan dalam bentuk hasil pengolahan dibandingkan dengan strandar kebisingan dari Keputusan Menteri Tenaga Kerja Nomor :KEP51/MEN/1999 tentang Nilai Ambang Batas Faktor Fisika di Tempat Kerja. Serta standar kriteria kebisingan yang ditetapkan oleh berbagai pihak berdasarkan Peraturan Menteri Kesehatan Republik Indonesia No.718/Men/Kes/Per/XI/1987, tentang kebisingan yang berhubungan dengan kesehatan dan kemudian menghasilkan kesimpulan.

\section{HASIL DAN PEMBAHASAN}

\section{A. Hasil Identifikasi Masalah}

Pengukuran kebisingan untuk setiap titik dilakukan pengulangan sebanyak 10 kali ulangan dengan interval waktu pengambilan data 5 detik agar diperoleh hasil yang akurat.
Tabel 1. Pembagian zona bising oleh menteri kesehatan [6]

\begin{tabular}{cccc}
\hline & Zona & \multicolumn{2}{c}{ Tingkat Kebisingan (dBA) } \\
\cline { 3 - 4 } No. & & $\begin{array}{c}\text { Maksimum yang } \\
\text { dianjurkan }\end{array}$ & $\begin{array}{c}\text { Maksimum yang } \\
\text { diperbolehkan }\end{array}$ \\
\hline 1 & A & 35 & 45 \\
2 & B & 45 & 55 \\
3 & C & 50 & 60 \\
4 & D & 60 & 79 \\
\hline
\end{tabular}

Tabel 1 menjelaskan bahwa Zona A diperuntukan bagi tempat penelitian, rumah sakit, tempat perawatan kesehatan dan sebagainya, Zona B diperuntukan perumahan, tempat pendidikan, rekreasi, dan sejenisnya, Zona C diperuntukan untuk perkantoran, pertokoan, perdagangan, pasar, dan sejenisnya serta Zona D industri, pabrik, stasiun kereta api, terminal bis, dan sejenisnya. Pada penelitian kali ini untuk menganalisis tentang getaran dan kebisingan pada alat kerja vibrating screen di PT. MIFA Bersaudara yang mana diklasifikasikan pada Zona D yang memiki maksimum yang di anjurkan 60 dBA dan maksimum yang diperbolehkan yaitu 79 dBA. Berikut ini tabel waktu maksimum untuk bekerja.

Tabel 2. Waktu maksimum bekerja [6]

\begin{tabular}{ccc}
\hline No. & $\begin{array}{c}\text { Tingkat Kebisingan } \\
(\mathrm{dBA})\end{array}$ & Pemaparan Harian \\
\hline 1 & 85 & $8 \mathrm{Jam}$ \\
2 & 88 & $4 \mathrm{Jam}$ \\
3 & 91 & $2 \mathrm{Jam}$ \\
4 & 94 & $1 \mathrm{Jam}$ \\
5 & 97 & 30 Menit \\
6 & 100 & 15 Menit \\
\hline
\end{tabular}

Pada pengukuran getaran menggunakan vibrationmeter. Pengukuran geratan dilakukan pada rangka atau dudukan alat kerja vibrating screen yang berhubungan langsung dengan operator yang mesin sedang dioperasikan. Pengukuran getaran dilakukan searah dengan sumbu $\mathrm{x}$, sumbu $\mathrm{y}$ dan sumbu $\mathrm{z}$ pada setiap titik pengukuran.

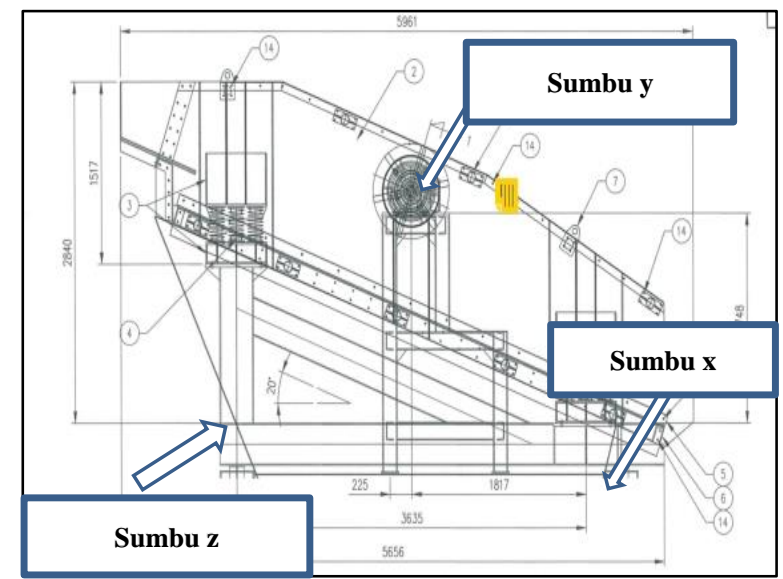

Gambar 1. Vibrating screen crusher FC 02 (tampak depan) 
berdasarkan titik pengukuran

Pegukuran dilakukan sebanyak 5 kali ulangan pada setiap kecepatan mesinnya setelah itu dilakukan analisis getaran dan dibandingan dengan standar batas paparan getaran yang diijinkan. Pengukuran tingkat kebisingan dilakukan pada sumber bising yaitu disekitaran titik terdekat pada vibrating screen crusher FC 02 saat beroperasi di PT. Mifa Bersudara. Untuk lebih jelasnya dapat dilihat pada Gambar 1.

\section{B. Analisis Tingkat Getaran pada Vibrating Screen Crusher}

Ambang waktu yang dapat diterima merupakan waktu yang masih diperbolehkan untuk memenuhi standar paparan yang diterima. Dengan kata lain perhitungan TVDV merupakan salah satu cara untuk mengetahui waktu maksimal yang diperolehkan dalam suatu getaran sehingga dapat memberi informasi bahkan meminimalisir dampak negative dari getaran tersebut[3].

$$
\mathrm{T}_{\mathrm{vdv}}=\mathrm{T} \mathrm{x}\left(\frac{\mathrm{VDV} \text { theres hold }}{\text { VDV measured }}\right) 4
$$

$\mathrm{T}=$ Durasi pajanan ( jam )

$\operatorname{VDV}_{\text {threshold }}=$ Nilai Standar VDV $\left(\mathrm{m} / \mathrm{s}^{1,40}\right)$

$\mathrm{VDV}_{\text {measured }}=$ Nilai perhitungan $\operatorname{VDV}\left(\mathrm{m} / \mathrm{s}^{1,40}\right)$

Hasil pengukuran tersebut dilakukan nilai rata- rata besaran tingkat getaran pada alat kerja Vibrating Screen di representasikan pada Gambar 2.

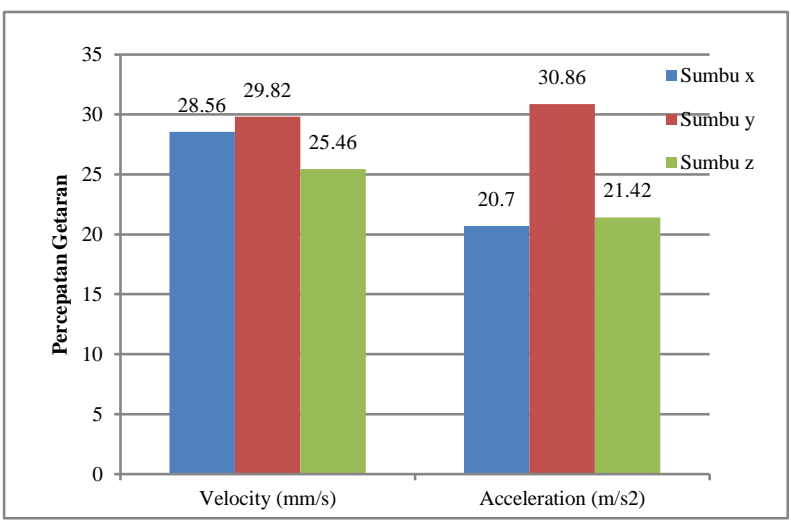

Gambar. 2 Nilai rata-rata getaran pada vibrating screen crusher FC 02

Berdasarkan gambar grafik diatas bahwa nilai getaran pada alat kerja Vibrating Screen sumbu x getaran yang di hasil kan pada dengan nilai velocity $28,56 \mathrm{~mm} / \mathrm{s}$ mengalami kenaikan pada sumbu y dengan nilai velocity $29,82 \mathrm{~mm} / \mathrm{s}$ dan pengalami penurunan pada sumbu $\mathrm{Z}$ dengan nilai velocity $25,46 \mathrm{~mm} / \mathrm{s}$, sedangkan pada percepatan (acceleration) pada sumbu x sebesar 20,7 $\mathrm{m} / \mathrm{s}^{2}$ mengalami lonjakan kenaikan dengan nilai Acceleration getaran rata- rata mencapai sebesar 30,86 $\mathrm{m} / \mathrm{s}^{2}$ pada sumbu y dan kembali mengalami penurunan pada sumbu $\mathrm{z}$ sengan nilai acceleration getaran rata-rata mencapai sebesar $21,42 \mathrm{~m} / \mathrm{s}^{2}$.
Berdasarkan standar getaran Keputusan Menteri Kesehatan Nomor 1405/MENKES/SK/XI/ 2002 tentang getaran yang berhubungan dengan kesehatan [5] dimana getaran mekanis dapat diartikan sebagai getaran yang ditimbulkan oleh alat-alat mekanis, dan sebagian getaran tersebut sampai ke tubuh manusia sehingga dapat menimbulkan gangguan yang tidak diinginkan oleh tubuh manusia. Dengan demikian acuan dalam penelitian yang peroleh mengacu pada batas ambang getaran yang sesuai standar, untuk lebih jelasnya ditunjukkan pada Tabel 3.

Tabel 3. Standar ambang batas pada getaran

\begin{tabular}{ccc}
\hline & \multicolumn{2}{c}{$\begin{array}{c}\text { Nilai Percepatan pada } \\
\text { Frekuensi Dominan }\end{array}$} \\
\cline { 2 - 3 } $\begin{array}{c}\text { Jumlah waktu } \\
\text { /Hari kerja }\end{array}$ & $\begin{array}{c}\text { Meter per detik kuadrat } \\
\text { Gram (m/det2) }\end{array}$ & Gram \\
4 Jam dan kurang & 4 & 0,4 \\
$\begin{array}{l}\text { dari 8 jam } \\
\text { 2 Jam dan kurang } \\
\text { dari 4 jam }\end{array}$ & 6 & 0,61 \\
$\begin{array}{l}\text { J Jam dan kurang } \\
\text { dari 2 jam } \\
\text { Kurang dari 1 jam }\end{array}$ & 8 & 0,81 \\
\hline
\end{tabular}

Sesuai data yang diperoleh dari hasil penelitian di PT. Mifa Bersudara dapat dihasilkan bahwa lama gentaran sesuai dengan standar yang diterima dengan jumlah waktu hari kerja per hari kerja dimana kategori 4 jam dan kurang dari 8 jam dengan nilai percepatan (getaran) pada frequensi dominan $4 \mathrm{~m} / \operatorname{det}^{2}$. Pada sumbu $\mathrm{x}$ dihasilkan bahwa rata-rata $0,3 \mathrm{~m} / \mathrm{det}^{2}$ yang mana sudah memenuhi/normal sesuai dengan standar yang diperbolehkan pada getaran pabrik industri. Sama halnya dengan sumbu $\mathrm{z}$ dihasilkan bahwa rata-rata $0,3 \mathrm{~m} / \mathrm{det}^{2}$ yang mana sudah memenuhi/normal sesuai dengan standar yang diperbolehkan. Akan tetapi berbeda dengan sumbu y dihasilkan bahwa rata-rata $0,5 \mathrm{~m} / \mathrm{det}^{2}$ yang mana memenuhi/tidak normal yang sesuai dengan standar yang diperbolehkan.

\section{Analisis Tingkat Kebisingan pada Vibrating Screen}

Dari hasil pengukuran kebisingan pada titik yang telah ditentukan disekitaran alat vibrating screen di ketahui rata-rata kebisingan. Pada pehitungan tingkat kebisingan pada alat kerja vibrating screen dilakukan 3 titik pengukuran dengan 5 kali pengulangan. Pada pengukuran tersebut dilakukannya 3 titik pengukuran dimana sumber bising tersebut berasal pada alat kerja vibrating screen. Pada titik pertama pengukuran dilakukan pada sisi kanan ujung vibrating screen dan pada pengkuran kedua dilakukan pada sisi kiri dekat dengan sumber bising bagian pada vibrating screen.

Tingkat kebisingan pada setiap titik pengukuran dengan melakukan 5 kali pengulangan disetiap sisi kanan dan kiri terdapat nilai rata-rata berkisar antara 98,7-104,1 dBA. Tingkat kebisingan tertinggi terdapat pada titik paling dekat dengan sumber bising pada alat kerja vibrating screen (sisi kiri) dengan tingkat kebisingan 104,1 dBA. Hal tersebut disebabkan pada titik 
pengukuran kebisingan sisi kanan merupakan sumber bising yang ada pada alat kerja vibrating screen. Sedangan pada tingkat kebisingan terendah pada titik pengukuran kebisingan sisi kanan yang mana titik terjauh dengan sumber bising sebesar 98,7 dBA. Berdasarkan tingkat kebisingan yang terukur kecepatan putaran motor pada alat kerja Vibrating Screen berbanding lurus dengan tingkat kebisingannya. Nilai tingkat kebisingan mesin tersebut memenuhi tingkatan standar kebisingan yang diisyaratkan oleh OSHA 1978, dimana tingkat kebisingan mesin produksi maksimal berada pada $75 \mathrm{db}$ sedangkan yang diisyarakatkan oleh OSHA 1978 maksimum berada pada tingkat $85 \mathrm{db}$ [8-9].data hasil pengukuran pada vibrating screen ditunjukkan pada Tabel 4

Tabel 4. Rata-rata intensitas kebisingan pada vibrating screen

\begin{tabular}{ccccc}
\hline \multirow{2}{*}{$\begin{array}{c}\text { Sisi } \\
\text { Kebisingan }\end{array}$} & \multicolumn{2}{c}{$\begin{array}{c}\text { Titik Pengukuran pada } \\
\text { Vibrating Screen } \\
\text { (dBA) }\end{array}$} & $\begin{array}{c}\text { Rata-Rata } \\
\text { keseluruh } \\
\text { an (dBA) }\end{array}$ \\
\cline { 2 - 4 } & 1 & 2 & 3 & 99,6 \\
\hline Kanan & 100,5 & 98,7 & 99,6 & 101,7 \\
\hline
\end{tabular}

Berdasarkan pada Tabel 4 di atas menjelaskan bahwa rata-rata keseluran pada tiga titik pengukuran dengan dua sisi kanan dan kiri menunjukan bahwa rata-rata keseluruhan kebisingan pada alat kerja vibrating screen menujukan sebesar 99,6 dBA pada sisi kanan dan pada sisi kiri sebesar 101,7 dBA kebisingannya. Sedangkan Berdasarkan Badan Standarisasi Nasional (BSN) dalam SNI 16-7063-2004 dan Peraturan Menteri Kesehatan Republik Indonesia No.718/ Men/Kes/ Per/ XI/ 1987, tentang kebisingan yang berhubungan dengan kesehatan [6] menyebutkan bahwa dalam katogori Zona D industri, pabrik, stasiun kereta api, terminal bus, dan sejenisnya. Nilai ambang batas maksimum yang dianjurkan sebesar $60 \mathrm{dBA}$ dan nilai maksimum yang diperbolehkan $79 \mathrm{dBA}$ dengan waktu maksimum bekerja nilai batas ambang kebisingan adalah $85 \mathrm{~dB}$ yang dianggap aman untuk sebagaian besar tenega kerja bila bekerja 8 jam/hari atau 40 jam/minggu. Dapat disajikan dalam Gambar 3.

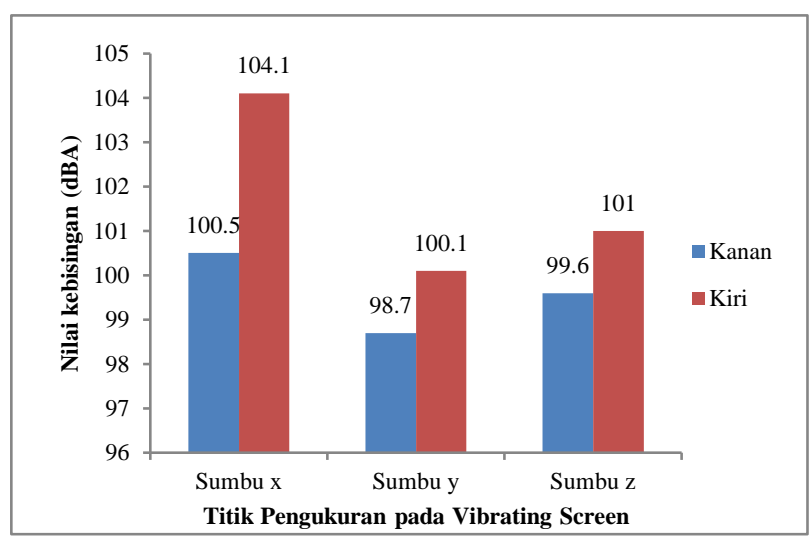

Gambar. 3 Nilai rata-rata kebisingan pada vibrating screen
Pada saat proses yang terjadi dilapangan saat melakukan magang di PT. MIFA Bersaudara, untuk nilai kebisingan yang terjadi rata-rata pada alat kerja vibrating screen menujukan sebesar 99,6 dBA pada sisi kanan dan pada sisi kiri sebesar 101,7 dBA kebisingannya. Sesuai dengan standarisasi Peraturan Menteri Kesehatan Republik Indonesia No.718/ Men/Kes/ Per/ XI/ 1987,tentang kebisingan yang berhubungan dengan kesehatan dikategorikan dengan tingkat kebisingannya yang mana berati pada sisi kanan pada alat kerja vibrating screen menujukan sebesar 99,6 dBA hanya boleh terkenan paparan 30 menit perhari serta pada sisi kiri sebesar 101,7 dBA berati hanya 15 menit saja dalam perharinya terkenan paparan kebisingan dari alat kerja vibrating screen ini. Untuk lebih jelasnya dapat dilihat pada Tabel 5.

Tabel 5. Lama pendengaran yang diizinkan kebisingan pada vibrating screen

\begin{tabular}{ccc}
$\begin{array}{c}\text { Sisi } \\
\text { Kebisingan }\end{array}$ & $\begin{array}{c}\text { Tingkat } \\
\text { Kebisingan } \\
\text { Rata-rata } \\
\text { (dBA) }\end{array}$ & $\begin{array}{c}\text { Lama } \\
\text { Pendenganan } \\
\text { Yang Diizinkan } \\
\text { (menit/hari) }\end{array}$ \\
\hline Kanan & 99,6 & 30 \\
Kiri & 101,7 & 15 \\
\hline
\end{tabular}

Berdasarkan pada tabel 5 diatas lama pendengaran yang diizinkan kebisingan pada Vibrating Screen crusher FC 02 sesuai dengan acuan Peraturan Menteri Kesehatan Republik Indonesia No.718/ Men/Kes/ Per/ XI/ 1987, tentang kebisingan yang berhubungan dengan kesehatan. Sehingga penggunaan alat kerja pada vibrating screen tidak boleh melebihi batas lama pendengaran yang diizinkan yakni 15-30 menit per harinya. Pemakaian alat kerja pada vibrating screen sebaiknya tidak melebihi batas waktu yang diizinkan untuk mejaga kesehatan dan keselamatan kerja dari operator maupun karyawan.

\section{KESIMPULAN}

Hasil penelitian yang dilaksanakan pada PT. MIFA Bersaudara dapat ditarik kesimpulan bahwa; Pengukuran getaran dan kebisingan alat kerja vibrating screen crusher FC 02 dilakukan searah dengan sumbu $\mathrm{x}$, sumbu y dan sumbu z pada setiap titik pengukuran. Berdasarkan nilai getaran pada alat kerja vibrating screen crusher FC 02 sumbu $\mathrm{x}$ getaran yang dihasilkan pada dengan nilai velocity $28,56 \mathrm{~mm} / \mathrm{s}$, sumbu y dengan nilai $29,82 \mathrm{~mm} / \mathrm{s}$ dan sumbu z nilai velocity $25,46 \mathrm{~mm} / \mathrm{s}$. Sedangkan pada acceleration pada sumbu x sebesar $20,7 \mathrm{~m} / \mathrm{s}^{2}$ mengalami kenaikan nilai $30,86 \mathrm{~m} / \mathrm{s}^{2}$ pada sumbu y dan penurunan sumbu z sebesar $21,42 \mathrm{~m} / \mathrm{s}^{2}$. Untuk nilai kebisingan pada alat kerja vibrating screen crusher $F C 02$ yaitu dua sisi kanan dan kiri menujukan sebesar 99,6 dBA pada sisi kanan dan pada sisi kiri sebesar 101,7 dBA , nilai kebisingan ini.menunjukan tingkat kebisingan melebihi batas maksimum yang dianjurkan yaitu $60 \mathrm{dBA}$ dan maksimum yang diperbolehkan $70 \mathrm{dBA}$. 


\section{SARAN/REKOMENDASI}

Operator disarankan ketika mengoperasikan alat kerja vibrating screen crusher FC 02 agar menggunakan APD yang baik seperti earmuff safety untuk mencegah terjadinya permasalahan kenyamanan, kesehatan, dan keselamatan kerja.

\section{REFERENSI}

[1] PT. MIFA Bersaudara (Persero), Industry | Update, Profil PT. MIFA Bersaudara, Aceh Barat, Website: http://www.mifacoal.co.id/id-id/, diakses tanggal 3 Maret 2021.

[2] A.J. Saputra, Analisis kebisingan peralatan pabrik dalam upaya peningkatan penaatan peraturan keselamatan dan kesehatan kerja PT. PUPUK KALTIM, Tesis, Universitas Diponegoro, 2007.

[3] S.A. Kurniawati, M. Yamin, Analisis kebisingan dan getaran mekanis pada mesin saccof harvester (studi kasus di kebun tebu cimahpar, Bogor, Jawa Barat). Jurnal Keteknikan Pertanian, 2013, 27(1).

[4] B. Suhardi, Perancangan sistem kerja dan ergonomi industri, Jakarta: Direktorat Pembinaan Sekolah Menengah Kejuruan, Direktorat Jenderal Manajemen Pendidikan Dasar dan Menengah, Departemen Pendidikan Nasional, 2008.

[5] A.A. Fadili, S. Solihin, E. Moralista, Pengaruh diameter wire screen terhadap produksi dan efisiensi vibrating screen di unit crushing plant batu andesit PT Nurmuda Cahaya Desa Batujajar Timur, Kecamatan Batujajar, Kabupaten Bandung Barat, Provinsi Jawa Barat, Prosiding Teknik Pertambangan, vol. 6, no. 1, 2020, pp 186-193.

[6] A.K. Hendrawan, Analisis kebisingan di bengkel kerja Akademi Maritim Nusantara. Saintara: Jurnal Ilmiah Ilmu-Ilmu Maritim, 5(1), 2020.

[7] Manullang, A. L. E., \& Handayani, N. U, Evaluasi pencahayaan, kebisingan, temperature dan getaran pada line 3 PT South Pasific Viscose. Industrial Engineering Online Journal, 4(3), 2015.

[8] H. Susanto, S. Ali, M. Khalil, Uji getaran rangka tabung sentrifugal mesin produksi santan kapasitas 10 liter per jam. Jurnal Mekanova: Mekanikal, Inovasi dan Teknologi, 7(1), 2021, 18-24.

[9] H. Susanto, A. Munawir, H. Darsan, Uji kebisingan pada motor listrik dan tabung sentifugal mesin produksi santan kapasitas 10 liter per jam, Jurnal Mekanova: Mekanikal, Inovasi dan Teknologi, 7(1), 2021, 50-57. 